\title{
Patient Awareness, Prevalence, and Risk Factors of Chronic Kidney Disease among Diabetes Mellitus and Hypertensive Patients at Jimma University Medical Center, Ethiopia
}

\author{
Kabaye Kumela Goro ${ }^{(D},{ }^{1}$ Amare Desalegn Wolide, ${ }^{2}$ \\ Fantu Kerga Dibaba, ${ }^{1}$ Fanta Gashe Fufa ${ }^{(D)}{ }^{1}$ Aster Wakjira Garedow (D), \\ Birtukan Edilu Tufa, ${ }^{3}$ and Eshetu Mulisa Bobasa ${ }^{1}$ \\ ${ }^{1}$ School of Pharmacy, Health Science Institute, Jimma University, Jimma, Ethiopia \\ ${ }^{2}$ School of Biomedical Science, Health Science Institute, Jimma University, Jimma, Ethiopia \\ ${ }^{3}$ School of Midwifery and Nursing, Health Science Institute, Jimma University, Jimma, Ethiopia \\ Correspondence should be addressed to Kabaye Kumela Goro; kabayekumela@gmail.com
}

Received 12 March 2019; Accepted 7 April 2019; Published 12 May 2019

Academic Editor: Maria Stangou

Copyright (C) 2019 Kabaye Kumela Goro et al. This is an open access article distributed under the Creative Commons Attribution License, which permits unrestricted use, distribution, and reproduction in any medium, provided the original work is properly cited.

\begin{abstract}
Background. There is an alarming rise of chronic kidney disease (CKD) prevalence globally, which is associated with significant morbidity and mortality necessitating special attention as one of the major public health problems. The burden of CKD disproportionately impacts low-income countries like Ethiopia where hypertension and diabetes mellitus, the two most important risk factors for CKD growth rate, are greatest. Objective. The aim of this study is to assess patient awareness, prevalence, and risk factors of chronic kidney disease among hypertensive and diabetes mellitus patients. Methods. Hospital based cross-sectional study design was conducted at Jimma University Medical Center among adult ( $\geq 18$ years) hypertensive and diabetes mellitus patients. Informed written consent was obtained from each participant and data was collected by interview and chart review; blood and urine samples were collected for CKD screening. Glomerular filtration rate (GFR) was estimated from serum creatinine using CKD epidemiology collaboration (CKD-EPI) equation, and CKD was defined using estimated GFR (e-GFR) and albuminuria. Multivariate logistic regression was used to identify independent predictors of CKD and $p$-value $<0.05$ considered statistically significant. Result. Mean ( $\pm \mathrm{SD}=$ standard deviation) age of participants was $54.81 \pm 12.45$ years and $110(52.9 \%)$ of them were male. Only $59(28.4 \%)$ of the participants had awareness about CKD and its risk factors. The prevalence of CKD was $26 \%$ (95\% CI; 20.3\%-31.8\%). Factors associated with chronic kidney disease were uncontrolled blood pressure (adjusted odds ratio $(A O R)=2.22,95 \% C I=1.01-4.76)$, fasting blood sugar $\geq 150 \mathrm{mg} / \mathrm{dl},(A O R=3.70,95 \% \mathrm{CI}=1.75-7.69)$, angiotensin converting enzyme inhibitors (ACEIs) nonusers, $(\mathrm{AOR}=4.35,95 \% \mathrm{CI}=1.96-10.0)$, poor knowledge of $\mathrm{CKD}$ ( $\mathrm{AOR}=3.69,95 \% \mathrm{CI}=1.48-9.20)$, and long duration of hypertension $(\mathrm{AOR}=4.55,95 \% \mathrm{CI}=1.72-11.11)$. Conclusion. Our study found out low level of patient awareness and high prevalence of CKD. The predictors of CKD were uncontrolled blood pressure, fasting blood sugar $>150 \mathrm{mg} / \mathrm{dl}$, long duration of hypertension, ACEIs nonusers, and poor knowledge about CKD.
\end{abstract}

\section{Introduction}

Chronic kidney disease (CKD), is defined as a progressive loss of kidney function occurring over several months to years; it is characterized by the gradual replacement of normal kidney structure with fibrotic tissues [1]. When these structural changes become conspicuous, it results in decreased kidneys' ability to process waste in the blood and perform other functions. During early stages patients may present with normal or slight decrease in Glomerular filtration rate (GFR) and Albuminuria; later it progresses, leading to endstage renal disease (ESRD) or kidney failure [1-4]. ESRD is irreversible and fatal, unless treated by dialysis or kidney transplant [5]. 
There is an alarming rise of CKD prevalence globally associated with significant morbidity and mortality, necessitating special attention as one of the growing public health problems. The prevalence of CKD in the general population is $13.4 \%$ globally [6] while pooled prevalence of CKD is $10.1 \%$ in the general population, $24.7 \%$ in hypertensive, and $16.6 \%$ among diabetes mellitus patients in Africa. [7]. According to the global burden of disease 2015 study, CKD was the $17^{\text {th }}$ leading cause of global years loss of life and one of the fastest rising major causes of death because overall mortality due to CKD has increased by $31.7 \%$ from 2005 to 015 [8].

Chronic Kidney disease is also associated with huge economic burden. In high-income countries treatment of end-stage kidney disease (ESRD) shares more than 2-3\% of their annual healthcare budget, while patients with ESRD represent only $0.03 \%$ of total population, and lower socioeconomic status is associated with greater risk of end-stage kidney disease [9]. In developing countries, the burden posed by CKD is much greater because of additional risks associated with poverty like: infections, hazardous work, poor education and poor maternal health combined with additional cost of screening and treatment where these costs have to be paid directly by patients [10].

Over half of all people requiring renal replacement therapy died due to a lack of access to dialysis or transplantation worldwide. Lack of access to renal replacement treatment in Africa, particularly middle and east Africa is the largest, where less than $3 \%$ of people requiring renal replacement therapy receive it [11]. As a result, people with end-stage kidney disease continue to die in the face of established treatment options and countries least equipped to provide dialysis or kidney transplantations are highly affected by the growing burden of CKD [12].

Early detection and treatment of chronic kidney disease can prevent or minimize complications associated with CKD [13]; however majority of CKD cases were not clinically recognized mainly because of the lack of patients' awareness about CKD and associated risk factors [14, 15]. It was conveyed that among 9772 adult patients admitted to a tertiary-care hospital, $40-70 \%$ of the patients were at risk for developing CKD [16]. Screening of patients at risk for CKD using objective measures found that $29 \%$ of those patients had $\mathrm{CKD}$, though, only $7 \%$ of them were aware of having kidney disease [17].

Thus, assessment of knowledge, attitudes, and practices could be an early step forward to determine the extent to which an individual can follow healthy behaviors [18]. Screening Clinical indicators of renal dysfunction is fundamental for the early detection of patients at risk for CKD; moreover, it is also imperative to increase patients' awareness in order to modify their lifestyle towards preventing the occurrence of the disease. Early screening and population education regarding CKD positively affected patients' understanding of CKD and medical outcomes [19]. Therefore, the current study is aimed at assessing patient awareness, prevalence, and risk factors for CKD among diabetes mellitus and hypertensive patients.

\section{Methods and Participants}

2.1. Study Setting and Population. The study was conducted at Jimma university medical center, which is the only referral hospital for the south west region. Adult (age $\geq 18$ years) diabetes mellitus and hypertensive patients on regular followup and those who signed informed written consent were recruited to the study. Confirmed chronic kidney disease, short follow-up period ( $<3$ months), incomplete patient chart, pregnant women, and critically ill patients were excluded from the study.

2.2. Study Design. Hospital based cross-section study design was used at JUMC to assess awareness, prevalence, and risk factors for chronic kidney disease among hypertensive and diabetic patients on regular follow-up. The sample size was calculated by using simple proportion formula with estimated prevalence of CKD among diabetes mellitus patients, $\mathrm{p}=18.1 \%$ [20], 95 confidence interval, and sample error of 5\%, when adjusted for total number of source population, $\mathrm{N}=3,000$, and final sample size, $\mathrm{n} \approx 208$

2.3. Data Collection Procedures. Data collection tool was developed after reviewing different literatures; the tool has three parts: the first part is sociodemographic and disease condition, second part has 7 yes or no questions assessing patients knowledge, and third part has 6 questions assessing attitude; the tool was translated to Afan Oromo and Amharic languages. Using these tools patients were interviewed to obtain respective information when they come for monthly check-up and medication refill. Patient's chart was also reviewed for information like medications, blood pressure, and serum glucose level. The last three months' FBS (fasting blood sugar) and BP (blood pressure) average were used assess glycemic and blood pressure control, respectively.

Average knowledge is when at least 4 questions were answered correctly out of 7 knowledge questions, and positive attitude is when patients agreed with at least three of the attitude statements. Patient awareness was assessed using knowledge and attitude; it is considered as patients have awareness about CKD if they have both average knowledge and positive attitude.

Laboratory technologists drained $3 \mathrm{cc}$ of vein blood according to standard vein puncture, and the serum creatinine level and blood urea nitrogen were determined using ARCHITECT c 8000 by kinetic alkaline picrate, and 10cc of middle stream urine was collected and urine dipstick was used to determine urine albumin level which was reported as negative, or +1 , to +4$)$. Glomerular filtration rate (GFR) was estimated using CKD -EPI question [21]; chronic kidney disease was defined using eGFR and presence of albuminuria and classified into five stages according to KDIGO classification system [2].

2.4. Ethics. The study protocol was approved by the institutional review board (IRB) of Jimma University, Institute of Health Sciences, and ethical clearance was obtained. Permission of data collection was granted with formal letter from chief executive director of JUMC. The purpose and 
protocol of this study was explained to participants and written informed consent was obtained from each patient. The privacy of personal information was protected and kept confidential. Codes were used for patient identification instead of names. Patients with abnormal findings were informed and referred to physicians for further investigation and appropriate management.

2.5. Data Analysis. Data was checked for completeness, grouped, then entered to EPI data, and exported to SPSS version 20 for analysis. Descriptive statistics like percentage and mean and standard deviation were used to present sociodemography and clinical characteristics of participants. Bivariate logistic regression was used to assess the crude association between independent variables and CKD and variables with $p$-value $\leq 0.25$ were considered for multivariate logistic regression. Finally backward conditional logistic regression was used to identify independent predictors of CKD and $p$-value $<0.05$ was considered statistically significant.

\section{Result}

A total of 208 hypertensive and diabetes mellitus patients were included in the study, of which 110 (52.9\%) of the participants were male with mean $( \pm$ SD) age of $54.81 \pm 12.45$ years. Majority of the study participants 145 (69.7\%) were married, 142(68.7\%) were rural dwellers, and 136 (65.4\%) were educated at least up to elementary level (see Table 1).

The mean $( \pm S D)$ systolic blood pressure and diastolic blood pressure of study participants were $136.6 \pm 15.7 \mathrm{mmHg}$ and $85 \pm 8.9 \mathrm{mmHg}$, respectively. Mean $(( \pm \mathrm{SD})$ fasting blood sugar was $145.6 \pm 52 \mathrm{mg} / \mathrm{dl}$ and more than half $114(54.8 \%)$ of the study participants had healthy body weight. Seventysix $(36.5 \%)$ of participants had average knowledge while 86 $(41.3 \%)$ had positive attitude towards chronic kidney disease. Majority $143(68.8 \%)$ of the study participants do not use social drugs like tobacco, alcohol, and Khat (see Table 2).

3.1. Patient Awareness of Chronic Kidney Disease. About 59 (28.4\%) of the participants had awareness about CKD and $76(36.5 \%)$ of the participants had average knowledge (see Table 2). Over half 109 (52.4\%) of the study participants knew that CKD is reduced ability of the kidneys to avoid waste from the blood; only $80(38.5 \%)$ and $92(44.2 \%)$ of the respondents knew that hypertension and diabetes mellitus are risk factors for chronic kidney disease, respectively. Knowledge of the participants regarding progressive nature of CKD and kidney failure treatment cost was very low. Overall, 86 (41.3\%) participants had positive attitude towards early detection and prevention of CKD; most 190 (72.1\%) of the respondents prefer to go to health facility if they have sign of CKD and 150 (91.3) agreed that renal function test shall be done despite absence of symptoms; however majority 149 (71.6\%) of the respondents believed renal function screening is costly (see Table 3).

3.2. Magnitude and Stages of CKD. The overall prevalence of chronic kidney disease was $26 \%$ with (95\% CI, 20.3\%-31.8\%);
TABLE 1: Sociodemographic characteristics of diabetes mellitus and hypertensive patients at JUMC.

\begin{tabular}{|c|c|c|}
\hline Characteristics & Number & Percent \\
\hline \multicolumn{3}{|l|}{ Age (year) } \\
\hline$<55$ & 101 & 48.6 \\
\hline$\geq 55$ & 107 & 51.4 \\
\hline \multicolumn{3}{|l|}{ Sex } \\
\hline Male & 110 & 52.9 \\
\hline Female & 98 & 47.1 \\
\hline \multicolumn{3}{|l|}{ Marital status } \\
\hline Married & 145 & 69.7 \\
\hline Single & 63 & 30.3 \\
\hline \multicolumn{3}{|l|}{ Educational level } \\
\hline No education & 72 & 34.6 \\
\hline Elementary School & 96 & 46.2 \\
\hline Secondary school & 28 & 13.5 \\
\hline College and above & 12 & 5.8 \\
\hline \multicolumn{3}{|c|}{ Average monthly income (ETB) } \\
\hline$<1000$ & 117 & 56.2 \\
\hline $1001-3000$ & 37 & 17.8 \\
\hline $3001-5000$ & 34 & 16.3 \\
\hline Above 5000 & 20 & 9.6 \\
\hline \multicolumn{3}{|c|}{ Source of health information } \\
\hline Health care providers & 151 & 72.6 \\
\hline Television and Radio & 49 & 23.6 \\
\hline Others & 8 & 3.8 \\
\hline \multicolumn{3}{|l|}{ Residence } \\
\hline Urban & 142 & 68.3 \\
\hline Rural & 66 & 31.7 \\
\hline
\end{tabular}

ETB: Ethiopian Birr.

of this, majority 41 (75.6) of the CKD were detected at early stage (normal or mildly decreased e- GFR with albuminuria), while $8(14.8 \%)$ were with moderately increased risk for chronic kidney disease and 5 (9.3\%) were high risk group (see Table 4).

3.3. Factors Associated with Chronic Kidney Disease. In crude analysis using bivariate logistic regression, age greater than 55 years, rural residence, ACEIs nonusers, poor CKD knowledge, negative attitude, long duration of hypertension, long duration of diabetes mellitus, social drug use, high level of fasting blood sugar, and uncontrolled blood pressure were associated significantly with chronic kidney disease.

Independent predictors for chronic kidney disease were identified using multivariate logistic regression; ACEIs nonusers, poor knowledge of CKD, long duration of hypertension, fasting blood sugar $\geq 150 \mathrm{mg} / \mathrm{dl}$, uncontrolled blood pressure ( $>140 / 90 \mathrm{mmHG})$ were found to be independent predictors of chronic kidney disease,

According to our finding, patients with uncontrolled blood pressure were 2.22 (AOR; 2.22 95\% CI 1.01-4.76) times at risk for chronic kidney disease than those with controlled blood pressure. Patients who were not using angiotensin 
TABLE 2: Knowledge, attitude, and clinical characteristics of diabetes mellitus and hypertensive patients at JUMC.

\begin{tabular}{|c|c|c|}
\hline Characteristics & $\begin{array}{c}\text { Number } \\
\text { (Mean }\end{array}$ & $\begin{array}{c}\text { Percent } \\
\text { (standard deviation) }\end{array}$ \\
\hline Systolic pressure & 136.6 & \pm 15.7 \\
\hline Diastolic pressure & 85.6 & \pm 8.9 \\
\hline Fasting blood sugar & 145.6 & \pm 51.2 \\
\hline Blood urea nitrogen & 26.6 & \pm 13.2 \\
\hline \multicolumn{3}{|l|}{ Urine albumin } \\
\hline Positive & 51 & 24.5 \\
\hline Negative & 157 & 74.5 \\
\hline \multicolumn{3}{|l|}{ BMI category $\left(\mathrm{Kg} / \mathrm{m}^{2}\right)$} \\
\hline Underweight $(<18.5)$ & 14 & 6.7 \\
\hline Healthy weight $18.5-24.9)$ & 114 & 54.8 \\
\hline Overweight (25-29.9) & 63 & 30.3 \\
\hline Obese $(>30)$ & 17 & 8.2 \\
\hline \multicolumn{3}{|l|}{ Social drug use } \\
\hline Users & 65 & 31.2 \\
\hline Non-Users & 143 & 68.8 \\
\hline \multicolumn{3}{|l|}{ Knowledge about CKD } \\
\hline Average knowledge & 76 & 36.5 \\
\hline Poor knowledge & 132 & 63.5 \\
\hline \multicolumn{3}{|l|}{ Attitude toward CKD } \\
\hline Positive attitude & 86 & 41.3 \\
\hline Negative attitude & 122 & 58.7 \\
\hline \multicolumn{3}{|c|}{ Duration of hypertension (year) } \\
\hline $0-5$ & 92 & 44.2 \\
\hline $6-10$ & 74 & 35.6 \\
\hline Above 10 & 42 & 20.2 \\
\hline \multicolumn{3}{|l|}{ Duration of DM } \\
\hline $0-5$ & 90 & 43.3 \\
\hline $6-10$ & 80 & 38.5 \\
\hline Above 10 & 38 & 18.3 \\
\hline \multicolumn{3}{|l|}{ Family Hx of Kidney disease } \\
\hline Positive & 42 & 20.2 \\
\hline Negative & 166 & 79.8 \\
\hline
\end{tabular}

CKD: chronic kidney disease, BMI: body mass index, DM: Diabetes mellitus, Family Hx: family history.

converting enzyme inhibitors (ACEIs) were 4.35 (AOR 4.35, 95\% CI 1.96-10.0) times likely to develop chronic kidney disease when compared to users (see Table 5).

\section{Discussion}

In our study we assessed patient awareness (knowledge, attitude), prevalence of $\mathrm{CKD}$, and its predictors among hypertensive and diabetes mellitus patients. Overall knowledge about CKD was low: only $36.5 \%$ of the participants have average knowledge which was similar with low knowledge level (mean=3.85) reported from community study in Tanzania [22], higher than what was reported from Nigeria where only $27 \%$ of study participants had good knowledge [23], but lower than that report from Jordan where $50 \%$ of the participants scored $>80 \%$ correct scores [14]. This difference might be due to difference in health literacy of the study population or difference in number and type of questions used to assess patients' knowledge. Regarding knowledge of CKD risk factors only $38.5 \%$ and $44.2 \%$ of participants knew hypertension and diabetes mellitus can cause CKD, respectively; this was in line with finding in Nigeria [23], which was $38.3 \%$ and $43.6 \%$, respectively, but higher than the report from Iran where only $12.7 \%$ of the respondents selected "unmanaged diabetes" and $14.4 \%$ selected "unmanaged hypertension" as "very likely to result in CKD" [24]. This disparity might be due to difference in study setting community versus facility based and the tools used were different. We used dichotomous question while it was Likert scale in the study from Iran.

Overall attitude favoring early detection and prevention of CKD was low; most 149 (71.6\%) of the participants believed kidney function screening is costly, though majority 190 $(90.3 \%)$ of the respondents agreed to seek modern medical care; this was in agreement with report from Tanzania. All $(100 \%)$ were willing to seek healthcare from a biomedical clinic and many participants with CKD were concerned about the health and economic impact of a diagnosis of kidney disease [22].

The prevalence of chronic kidney disease was found to be $26 \%$ (95\% CI:20.07\%-31.93\%) which was corresponding to the report from UK which was $27.5 \%$ [25] higher than previous reports from similar setting, $18.1 \%$ from southern part of Ethiopia [21] and 20.8\% from Gondar [26], but lower than the prevalence reported from Spain where the prevalence of CKD among both diabetic and hypertensive patients was $31.22 \%$ [27] and prevalence of CKD among type2 DM in USA [28]. These discrepancies might be due to difference in the study population; in the first two studies the study population was diabetic patients, while it might be due to studying setting difference and large sample size used in Spain and USA studies.

In our study, fasting blood sugar $>150 \mathrm{mg} / \mathrm{dl}$ was independently associated with chronic kidney disease (AOR; 3.70, 95\% CI; 1.75-7.69); this was similar with report from USA were high level of Hemoglobin Alc was associated with CKD [28], and in southern Ethiopia uncontrolled diabetes mellitus was independently associated with CKD. [20], while it was only associated with bivariate logistic regression according the study from Gondar [26].

This study also revealed that long duration of hypertension and uncontrolled blood pressure (BP> 140/90 $\mathrm{mmHg}$ ) were independent predictors of $\mathrm{CKD}$; this supports previous reports, where uncontrolled blood pressure was associated with high risk of CKD $[20,28]$ and among the participants at risk for CKD, 113 (83.0\%) had poorly controlled hypertension [22]. It was also in line with earlier findings, where long-term, uncontrolled, high blood pressure was found to be initiating factor for high intraglomerular pressure, leading to impairing glomerular filtration, microalbuminuria, or proteinuria $[29$, 30]. 
TABLE 3: Knowledge and attitude of DM and hypertensive patients about CKD at JUMC.

\begin{tabular}{|c|c|c|}
\hline \multirow[t]{2}{*}{ Knowledge Questions } & \multicolumn{2}{|c|}{ Response, Number (\%) } \\
\hline & Yes & No \\
\hline CKD is reduced ability of the kidneys to avoid waste from the blood & $109(52.4)$ & $99(47.6)$ \\
\hline Chronic kidney disease may not have any symptom until advanced & $62(29.8)$ & $146(70.2)$ \\
\hline High blood pressure can cause chronic kidney disease & $80(38.5)$ & $128(61.5)$ \\
\hline Diabetes mellitus can cause Chronic kidney disease & $92(44.2)$ & $116(55.8)$ \\
\hline Chronic kidney disease progresses to kidney failure & $40(19.2)$ & $168(80.8)$ \\
\hline Kidney failure is fatal if not treated by dialysis or kidney transplant & $52(25)$ & $156(75)$ \\
\hline Kidney failure treatment costs more than kidney function screening & 20(9.6) & $188(90.4)$ \\
\hline Attitude questions & Agree & Disagree \\
\hline Kidney function test is necessary though there is no sign of CKD & $150(72.1)$ & $58(27.9)$ \\
\hline It is not too expensive to have a kidney screening test. & $59(28.4)$ & $149(71.6)$ \\
\hline Chronic kidney disease carries high risk of death & $98(47.1)$ & $110(52.9)$ \\
\hline I will go to a health facility if I have signs of kidney disease & $190(91.3)$ & $18(8.7)$ \\
\hline It is possible to prevent chronic kidney disease & $120(57.7)$ & $488(2.3)$ \\
\hline Early detection of CKD is important to slow its progress & $162(77.9)$ & $46(22.1)$ \\
\hline
\end{tabular}

TABLE 4: Prevalence and stage of chronic kidney disease of diabetes mellitus and hypertensive patients at JUMC.

\begin{tabular}{lccc}
\hline Stage of CKD & Description & eGFR (ml/min/1.73m2) & Number $(\%)$ \\
\hline G1 & Normal or high with albuminuria & $\geq 90$ & $13(6.25)$ \\
G2 & Mildly decreased with albuminuria & $60-89$ & $28(13.5)$ \\
G3a & Mildly to moderately decreased & $45-59$ & $8(3.8)$ \\
G3b & Moderately to severely decreased & $30-44$ & $5(2.4)$ \\
G4 & Severely decreased & $15-29$ & 0 \\
G5 & Kidney failure & $<15$ & 0 \\
Total & & & $54(26)$ \\
\hline
\end{tabular}

eGFR: estimated glomerular filtration rate using CKD-EPI equation.

Use of ACEIs in the management of hypertension was found to be protective in the current study (AOR; 4.35, 95\% CI; 1.96-10) which supported previous studies [31] even though the study populations are not the same. Patient knowledge was independently associated (AOR; 3.69, 95\% CI 1.48-9.20) with chronic kidney disease. This was similar with report from Palestine which showed higher total knowledge score was associated with CKD prevention $(\mathrm{p}<0.001)$ [32].

Age was significantly associated with bivariate logistic regression however not significantly associated with the final analysis which was different from most findings [20, 24, 26]. This difference might be due to small sample size of the current study. Other factors like duration of diabetes mellitus and place of residence were significant in the crude analysis only, while sex, family history of kidney disease, body mass index were not significantly associated.

Our study used cross-sectional study design; temporal relationship between risk factors and the outcome cannot be determined. Single measurement of serum creatinine and urine albumin was used to define CKD; semiquantitative urine albumin was used and so could not grade level of albuminuria, and the assessment of knowledge and attitude was based on self-report with possible risk of bias; we used "yes" or" no" and "agree and disagree" type of questions which limit possible answer of the respondents.

Despite these limitations, the finding of this study can be used as input for researchers and healthcare providers because as to our knowledge there was no prior study assessing patient awareness of CKD and risk factors among patients with both hypertension and DM; it will greatly contribute to increasing awareness of chronic kidney disease and its risk factors.

\section{Conclusion}

Our study found out low level of patient awareness of chronic kidney disease and its risk factors among patients with both hypertension and diabetes mellitus. The prevalence of chronic kidney disease was high and uncontrolled blood pressure, high fasting blood sugar, long duration of hypertension, ACEIs nonusers, and poor knowledge about CKD were found to be independent predictors for chronic kidney disease. Working toward increasing patient awareness 
TABLE 5: Independent variables associated with CKD among diabetes mellitus and hypertensive patients at JUMC.

\begin{tabular}{|c|c|c|c|c|c|c|}
\hline \multirow{2}{*}{ Variable } & \multicolumn{2}{|c|}{ CKD } & \multicolumn{2}{|c|}{ Bivariate analysis } & \multicolumn{2}{|c|}{ Multivariate analysis } \\
\hline & Yes, N (\%) & NO N (\%) & COR $(95 \% \mathrm{CI})$ & $\mathrm{P}$-value & AOR $(95 \% \mathrm{CI})$ & P-value \\
\hline \multicolumn{7}{|l|}{ Sex: } \\
\hline Female & $24(11.5)$ & $74(35.6)$ & 1 & & & \\
\hline Male & $30(14.4)$ & $80(38.5)$ & $1.12(0.62-2.12)$ & 0.65 & & \\
\hline \multicolumn{7}{|l|}{ Age(years) } \\
\hline$<55$ & $19(9.1)$ & $82(39.4)$ & 1 & & & \\
\hline$>/=55$ & $35(16.8)$ & $72(34.6)$ & $2.08(1.10-4.00)$ & 0.02 & & \\
\hline \multicolumn{7}{|l|}{ Marital status } \\
\hline Married & $37(17.8)$ & $108(5.2)$ & $0.93(0.47-1.81)$ & & & \\
\hline Single & $17(8.2)$ & $46(22.1)$ & 1 & 0.83 & & \\
\hline \multicolumn{7}{|c|}{ Family Hx of kidney disease } \\
\hline Absent & $32(15.4)$ & $122(58.7)$ & 1 & & & \\
\hline Present & $10(4.8)$ & $44(21.2)$ & $0.87(0.39-1.91$ & 0.72 & & \\
\hline \multicolumn{7}{|l|}{ Residence: } \\
\hline Urban & $31(14.9)$ & $111(54.1)$ & 1 & & & \\
\hline Rural & 23(11.6) & 4320.7) & $1.92(1.01-3.70)$ & 0.048 & & \\
\hline \multicolumn{7}{|l|}{ ACEIs/ARBS } \\
\hline Users & 29(13.9) & $128(61.5)$ & 1 & $<0.001$ & 1 & \\
\hline Non users & $25(12.0)$ & $26(12.5)$ & $4.17(2.13-8.33)$ & & 4.35(1.960-10.0) & $<0.001$ \\
\hline \multicolumn{7}{|l|}{ CKD knowledge } \\
\hline Average & $8(3.8)$ & $69(33.2)$ & 1 & & 1 & \\
\hline Poor & $46(22.1)$ & $85(40.9)$ & $4.67(2.07-10.55)$ & $<0.001$ & $3.69(1.48-9.20)$ & 0.005 \\
\hline \multicolumn{7}{|c|}{ Attitude toward CKD } \\
\hline Positive & $12(5.8)$ & $74(35.6)$ & 1 & & & \\
\hline Negative & $42(20.2)$ & $80(38.5)$ & $3.24(1.58-6.62)$ & & & \\
\hline \multicolumn{7}{|l|}{ Social drug use } \\
\hline Non users & $30(14.6)$ & $113(54.3)$ & 1 & & & \\
\hline Users & $24(11.7)$ & $41(19.7)$ & $2.22(1.16-4.17)$ & 0.016 & & \\
\hline \multicolumn{7}{|c|}{ Duration of hypertension } \\
\hline$\leq 5$ years & $18(8.8)$ & $74(36.1)$ & 1 & 0.007 & 1 & 0.007 \\
\hline $6-10$ years & $23(11.2)$ & $57(27.4)$ & $1.23(0.58-2.59)$ & 0.59 & $3.03(1.18-7.69)$ & 0.02 \\
\hline$>10$ years & $13(6.3)$ & 23(11.1) & $3.39(1.53-7.53$ & 0.003 & 4.55(1.72-11.11) & 0.002 \\
\hline \multicolumn{7}{|l|}{ Duration of DM } \\
\hline$\leq 5$ years & $18(8.8)$ & $72(34.6)$ & $0.48(0.21-1.12$ & 0.19 & & \\
\hline $6-10$ years & $17(8.2)$ & $57(27.4)$ & $0.78(0.34-1.77)$ & 0.09 & & \\
\hline$>10$ years & $19(9.1)$ & $25(12.2)$ & 1 & 0.55 & & \\
\hline \multicolumn{7}{|c|}{ Fasting blood sugar } \\
\hline$\leq 150 \mathrm{mg} / \mathrm{dl}$ & $24(11.5)$ & $110(52.9)$ & 1 & $<0.001$ & 1 & \\
\hline$>150 \mathrm{mg} / \mathrm{dl}$ & $30(14.4)$ & $44(21.2)$ & $3.13(1.64-5.88)$ & & $3.70(1.75-7.69)$ & 0.001 \\
\hline \multicolumn{7}{|c|}{ Blood pressure control } \\
\hline Controlled & $31(14.9)$ & $119(58.0)$ & 1 & & 1 & \\
\hline Uncontrolled & $22(10.6)$ & $35(16.8)$ & $2.44(1.23-4.23)$ & 0.009 & $2.22(1.01-4.76)$ & 0.046 \\
\hline
\end{tabular}

ACEIs/ARBs: Angiotensin converting enzyme inhibitors/angiotensin receptor blockers, family Hx: family history.

and screening for $\mathrm{CKD}$ at regular intervals among high risk groups is paramount to recognize chronic kidney disease at early stage before it progresses to kidney failure.

\section{Data Availability}

The data used to support the findings of this study are available from the corresponding author upon request.

\section{Conflicts of Interest}

The authors declare there is no conflict of interest.

\section{Acknowledgments}

We would like to express our appreciation to the study participants for their willingness to give samples and required information and staff of diabetes and hypertension clinic of Jimma 
University Medical Center for their cooperation during data collection process. We would also like to acknowledge Jimma University for providing the financial support.

\section{References}

[1] J. DiPiro, R. Talbert, G. Yee, G. Matzke, B. Wells, and L. Posey, Pharmacotherapy, McGraw-Hill Publishing, New York, NY, USA, 2011.

[2] A. Whaley-Connell, J. R. Sowers, P. A. McCullough et al., "Diabetes mellitus and CKD awareness: the kidney early evaluation program (KEEP) and national health and nutrition examination survey (NHANES)," American Journal of Kidney Diseases, vol. 53, Supplement 4, pp. S11-S21, 2009.

[3] G. Eknoyan, N. Lameire, K. Eckardt, B. Kasiske, D. Wheeler, A. Levin et al., "KDIGO 2012 clinical practice guideline for the evaluation and management of chronic kidney disease," Kidney International Supplements, vol. 3, no. 1, pp. 5-14, 2013.

[4] A. Levin and M. Rocco, "KDOQI clinical practice guidelines and clinical practice recommendations for diabetes and chronic kidney disease," American Journal of Kidney Diseases, vol. 49, no. 2, pp. S10-S179, 2007.

[5] National Kidney Foundation Inc., "About chronic kidney disease," 2013, https://www.kidney.org/atoz/content/about-chronickidney-disease\#ckd.

[6] N. R. Hill, S. T. Fatoba, J. L. Oke et al., "Global prevalence of chronic kidney disease - a systematic review and meta-analysis," PLoS ONE, vol. 11, no. 7, Article ID e0158765, 2016.

[7] S. Abd ElHafeez, D. Bolignano, G. D’Arrigo, E. Dounousi, G. Tripepi, and C. Zoccali, "Prevalence and burden of chronic kidney disease among the general population and high-risk groups in Africa: a systematic review," BMJ Open, vol. 8, no. 1, Article ID e015069, 2018.

[8] H. Wang, M. Naghavi, C. Allen et al., "GBD mortality and causes of death collaborators. Global, regional, and national life expectancy, all-cause mortality, and cause-specific mortality for 249 causes of death, 1980-2015: a systematic analysis for the global burden of disease study 2015," The Lancet, vol. 388, pp. 1459-1544, 2016.

[9] W. G. Couser, G. Remuzzi, S. Mendis, and M. Tonelli, "The contribution of chronic kidney disease to the global burden of major noncommunicable diseases," Kidney International, vol. 80, no. 12, pp. 1258-1270, 2011.

[10] J. M. Norton, M. M. Moxey-Mims, P. W. Eggers et al., "Social determinants of racial disparities in CKD," Journal of the American Society of Nephrology, vol. 27, no. 9, pp. 2576-2595, 2016.

[11] T. Liyanage, T. Ninomiya, V. Jha et al., "Worldwide access to treatment for end-stage kidney disease: a systematic review," Lancet, vol. 385, pp. 1975-1982, 2015.

[12] B. L. Neuen, S. J. Chadban, A. R. Demaio, D. W. Johnson, and V. Perkovic, "Chronic kidney disease and the global NCDs agenda," BMJ Global Health, vol. 2, no. 2, Article ID e000380, 2017.

[13] National Kidney Foundation, "K/DOQI clinical practice guidelines for chronic kidney disease: evaluation, classification and stratification," American Journal of Kidney Disease, vol. 39, Supplement 1, pp. S1-S266, 2002.

[14] A. Khalil and M. Abdalrahim, "Knowledge, attitudes, and practices towards prevention and early detection of chronic kidney disease," International Nursing Review, vol. 61, no. 2, pp. 237-245, 2014.
[15] P. A. McCullough, W. W. Brown, M. R. Gannon et al., "Sustainable community-based CKD screening methods employed by the national kidney foundation's kidney early evaluation program (KEEP)," American Journal of Kidney Diseases, vol. 57, Supplement 2, no. 3, pp. S4-S8, 2011.

[16] M. Ferris, D. A. Shoham, M. Pierre-Louis, L. Mandhelker, R. K. Detwiler, and A. V. Kshirsagar, "High prevalence of unlabeled chronic kidney disease among inpatients at a tertiary-care hospital," The American Journal of the Medical Sciences, vol. 337, no. 2, pp. 93-97, 2009.

[17] J. A. Vassalotti, L. A. Stevens, and A. S. Levey, "Testing for chronic kidney disease: a position statement from the national kidney foundation," American Journal of Kidney Diseases, vol. 50, no. 2, pp. 169-180, 2007.

[18] A. K. Bello, J. Peters, J. Wight, and M. El Nahas, “The kidney evaluation and awareness program in sheffield (KEAPS): a community-based screening for microalbuminuria in a british population," Nephron Clinical Practice, vol. 116, no. 2, pp. c95c103, 2010.

[19] S. Wei, Y. Chang, L. Mau et al., "Chronic kidney disease care program improves quality of pre-end-stage renal disease care and reduces medical costs," Nephrology, vol. 15, no. 1, pp. 108115, 2010.

[20] T. Fiseha, M. Kassim, and T. Yemane, "Prevalence of chronic kidney disease and associated risk factors among diabetic patients in Southern Ethiopia," American Journal of Health Research, vol. 2, no. 4, pp. 216-221, 2014.

[21] A. S. Levey, L. A. Stevens, C. H. Schmid et al., "A new equation to estimate glomerular filtration rate," Annals of Internal Medicine, vol. 150, no. 9, pp. 604-612, 2009.

[22] J. W. Stanifer, E. L. Turner, J. R. Egger et al., "Knowledge, attitudes, and practices associated with chronic kidney disease in Northern Tanzania: a community-based study," PLoS ONE, vol. 11, no. 6, Article ID e0156336, 2016.

[23] R. Oluyombo, O. E. Ayodele, P. O. Akinwusi et al., "Awareness, knowledge and perception of chronic kidney disease in a rural community of South-West Nigeria," Nigerian Journal of Clinical Practice, vol. 19, no. 2, pp. 161-169, 2016.

[24] P. Roomizadeh, D. Taheri, A. Abedini et al., "Limited knowledge of chronic kidney disease and its main risk factors among Iranian community: an appeal for promoting national public health education programs," International Journal of Health Policy and Management, vol. 2, no. 4, pp. 161-166, 2014.

[25] J. P. New, R. J. Middleton, B. Klebe et al., "Assessing the prevalence, monitoring and management of chronic kidney disease in patients with diabetes compared with those without diabetes in general practice," Diabetic Medicine, vol. 24, no. 4, pp. 364-369, 2007.

[26] S. Damtie, B. Biadgo, H. W. Baynes et al., "Chronic kidney disease and associated risk factors assessment among diabetes mellitus patients attending at university of Gondar Hospital, Northwest Ethiopia," Ethiopian Journal of Science, vol. 28, no. 6, p. 691, 2018.

[27] G. Alemán-Vega, I. Gómez Cabañas, L. Reques Sastre, J. Rosado Martín, E. Polentinos-Castro, and R. Rodríguez Barrientos, "Prevalence and risk of progression of chronic kidney disease in diabetics and hypertensive patients followed by primary care physicians," Nefrología (English Edition), vol. 37, no. 3, pp. 343345, 2017.

[28] B. Wu, K. Bell, A. Stanford et al., "Understanding CKD among patients with T2DM: prevalence, temporal trends, and 
treatment patterns- NHANES 2007-2012," BMJ Open Diabetes Research \& Care, vol. 4, no. 1, 2016.

[29] W. F. Keane and G. Eknoyan, "Proteinuria, albuminuria, risk, assessment, detection, elimination (PARADE): a position paper of the National Kidney Foundation," American Journal of Kidney Diseases, vol. 33, no. 5, pp. 1004-1010, 1999.

[30] T. Yoshioka, H. G. Rennke, D. J. Salant, W. M. Deen, and I. Ichikawa, "Role of abnormally high transmural pressure in the permselectivity defect of glomerular capillary wall: a study in early passive Heymann nephritis," Circulation Research, vol. 61, no. 4, pp. 531-538, 1987.

[31] L. C. van Vark, M. Bertrand, K. M. Akkerhuis et al., "Angiotensin-converting enzyme inhibitors reduce mortality in hypertension: a meta-analysis of randomized clinical trials of renin-angiotensin-aldosterone system inhibitors involving 158 998 patients," European Heart Journal, vol. 33, no. 16, pp. 20882097, 2012.

[32] H. H. Sa’adeh, R. N. Darwazeh, A. A. Khalil, and S. H. Zyoud, "Knowledge, attitudes and practices of hypertensive patients towards prevention and early detection of chronic kidney disease: a cross sectional study from Palestine," Clinical Hypertension, vol. 24, no. 1, p. 6, 2018. 


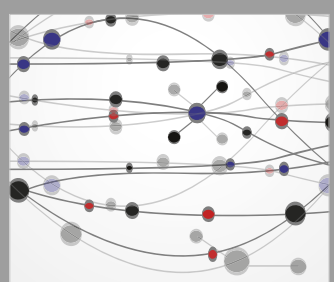

The Scientific World Journal
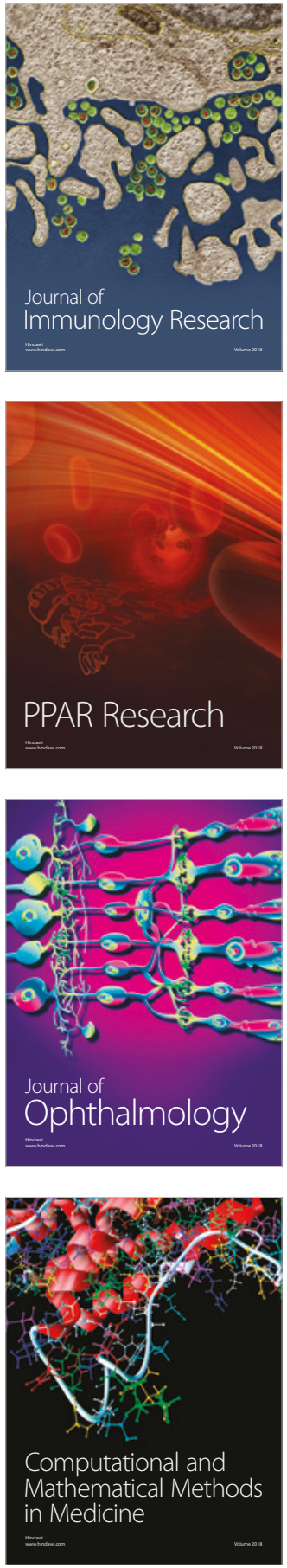

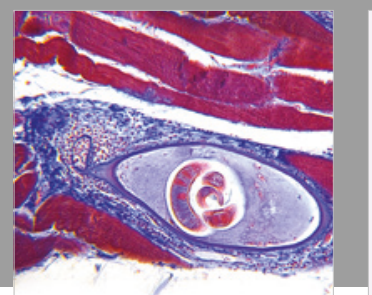

Gastroenterology Research and Practice

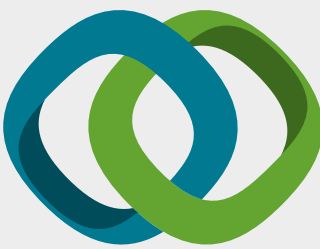

\section{Hindawi}

Submit your manuscripts at

www.hindawi.com
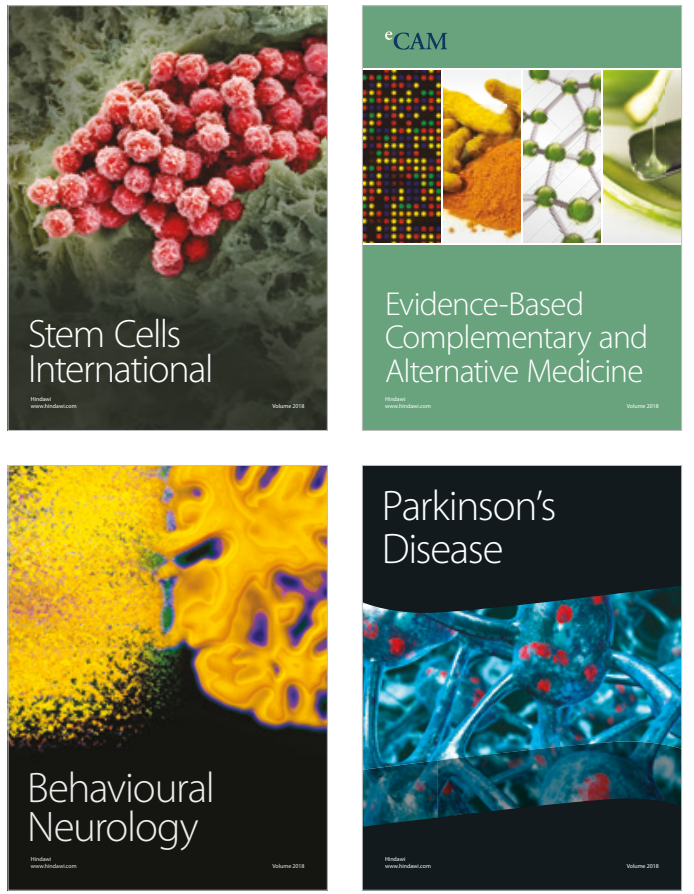

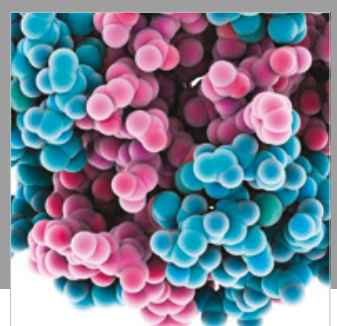

ournal of

Diabetes Research

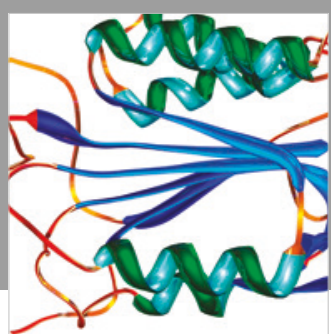

Disease Markers
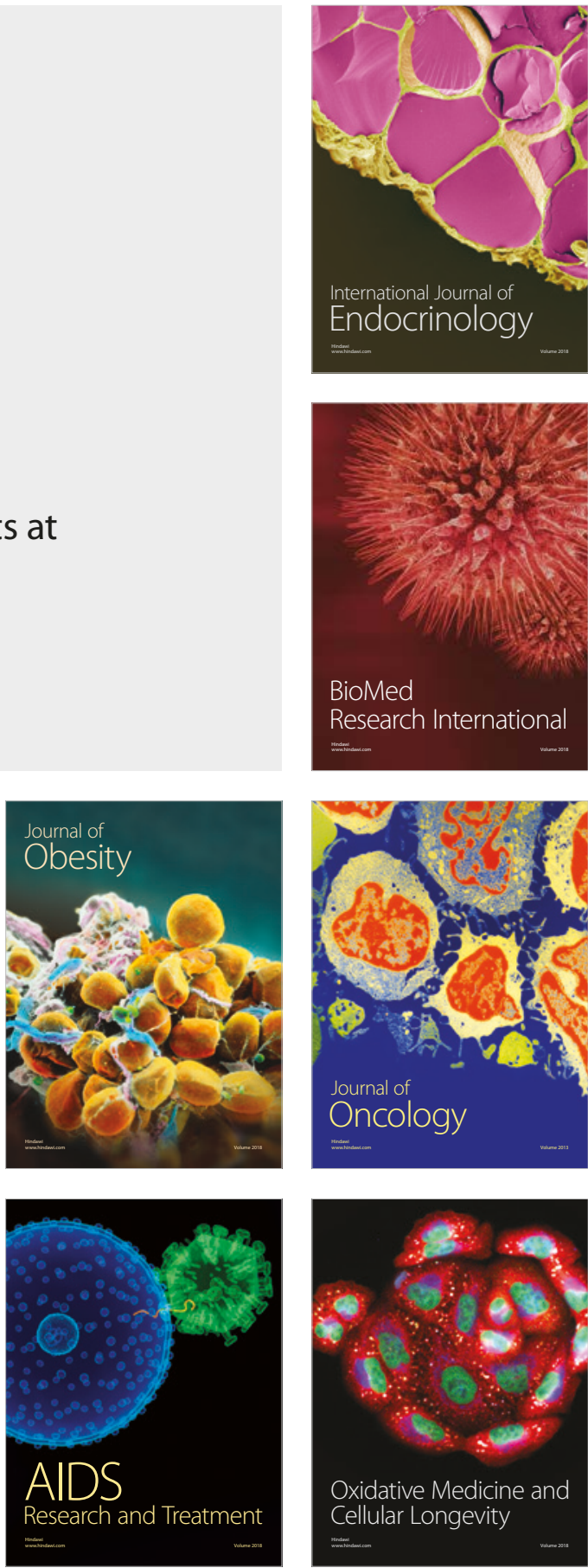